\title{
SYNOVECTOMY OF THE KNEE IN JUVENILE CHRONIC ARTHRITIS
}

\author{
A RETROSPECTIVE, CONSECUTIVE FOLLOW-UP STUDY \\ URBAN RYDHOLM, RENATE ELBORGH, JONAS RANSTAM, ASTRID SCHRÖDER, HELENA SVANTESSON, \\ LARS LIDGREN
}

From the University Hospital in Lund, Sweden

\begin{abstract}
We report 60 synovectomies of the knee in 51 children with juvenile chronic arthritis. Synovitis had been present for an average of 5 years and the average age at operation was 13 years. Results were evaluated in terms of pain, knee movement, relapse of synovitis and radiological change during a follow-up averaging 7.5 years.

The relief of pain was rewarding and there was a slight postoperative gain in range of knee movement in most cases. The older the patient at onset of disease, the greater the risk of pain during follow-up. Progressive joint destruction was more common in younger patients, those with systemic or polyarticular disease, and those with highly active disease at the time of operation. Recurrence of synovitis was more frequent in patients who had their operation in a phase of high disease activity; this occurred most often in patients with polyarticular disease.
\end{abstract}

Some promising long-term results after synovectomy of the knee for adult rheumatoid arthritis have recently been reported (Brattström 1985). Synovectomy for juvenile chronic arthritis (JCA) of the knee is less well reported, and opinions differ on the value of the operation and on timing and technique (Eyring 1968; Fink $e t$ al. 1969: Eyring, Longert and Bass 1971; Jani and Waigand 1971; Kampner and Ferguson 1972; McMaster 1972; Granberry and Brewer 1974; Granberry 1977; Roles 1978; Roles, Arden and Ansell 1978). Some authors have hesitated to operate on very young children for fear of postoperative growth disturbance, loss of movement, and lack of co-operation from the patient (Jani and Waigand 1971; Roles 1978).

Both Fink et al. (1969) and Berger et al. (1979) have reported radiographic improvement after synovectomy but the operation has usually been regarded as palliative rather than curative, its aims being to relieve pain and delay loss of mobility until remission occurs, or to postpone an arthroplasty (Rydholm, Boegård and Lidgren 1985). The chance of spontaneous remission and the generally good prognosis in two-thirds of all cases of JCA (Laaksonen 1966; Eyring et al. 1971) makes the

U. Rydholm. MD. Orthopaedic Surgeon

R. Elborgh. MD. Rheumatologist

J. Ranstam. BSc. Statistician

A. Schröder. MD. Rheumatologist

H. Svantesson. MD. Rheumatologist

L. Lidgren. MD. Orthopaedic Surgeon

University Hospital. S 22185 Lund. Sweden.

Requests for reprints should be sent to Dr U. Rydholm.

(. 1986 British Editorial Society of Bone and Joint Surgery $0301.620 \times 862058 \$ 2.00$ timing and the evaluation of the operation difficult. The outcome of the disease cannot be predicted in the individual case; if a joint is destined to recover spontaneously, operation is unnecessary.

We have reviewed 60 synovectomies of the knee in 51 patients with JCA, and tried to define those factors which affect the long-term result.

\section{MATERIAL AND METHODS}

Sixty synovectomies of the knee were performed for 51 patients with JCA at the Department of Orthopaedic Surgery in Lund from 1969 to 1980. Full medical records were available. The indications for operation were: persistent swelling with pain, epiphyseal overgrowth, valgus deformity, and progressive loss of movement. All patients of 16 years and under were included: nine had bilateral operations, and there were 30 left and 30 right knees. There were 16 boys and 35 girls. The mean age at onset of the disease was 5 years (range 1 to 14 years), and the mean age at operation was 13 years, with a range of 4 to 16 years, as shown in Figure 1. Synovitis had been present for an average of 5 years, ranging from 1 to 14 years (Fig. 2).

Four types of JCA were recognised: systemic, polyarticular, oligo-articular and monarticular. At the time of operation one knee was associated with systemic disease, 32 with polyarticular disease, 19 with oligoarticular disease, and in 8 the symptoms and signs were monarticular. The follow-up averaged 7.5 years (range 2 to 13 years).

Operations were performed under general or spinal anaesthesia. A medial parapatellar incision was used and 


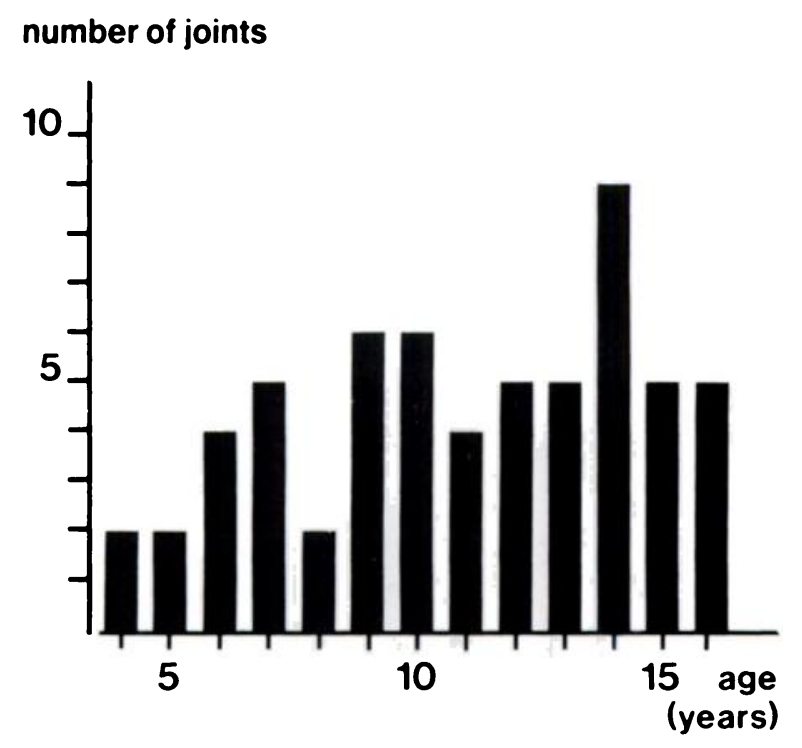

Fig. 1

Age at the time of synovectomy operations on 60 knees in patients with juvenile chronic arthritis.

a subtotal synovectomy performed, leaving the menisci in place unless they had been severely damaged by pannus. In some cases an additional lateral parapatellar incision was used to facilitate a more complete synovectomy. After operation a Robert Jones bandage was applied and isometric quadriceps exercises were started as soon as postoperative pain had subsided. The knee was manipulated and mobilised under general anaesthesia if either 90 or the pre-operative range of flexion

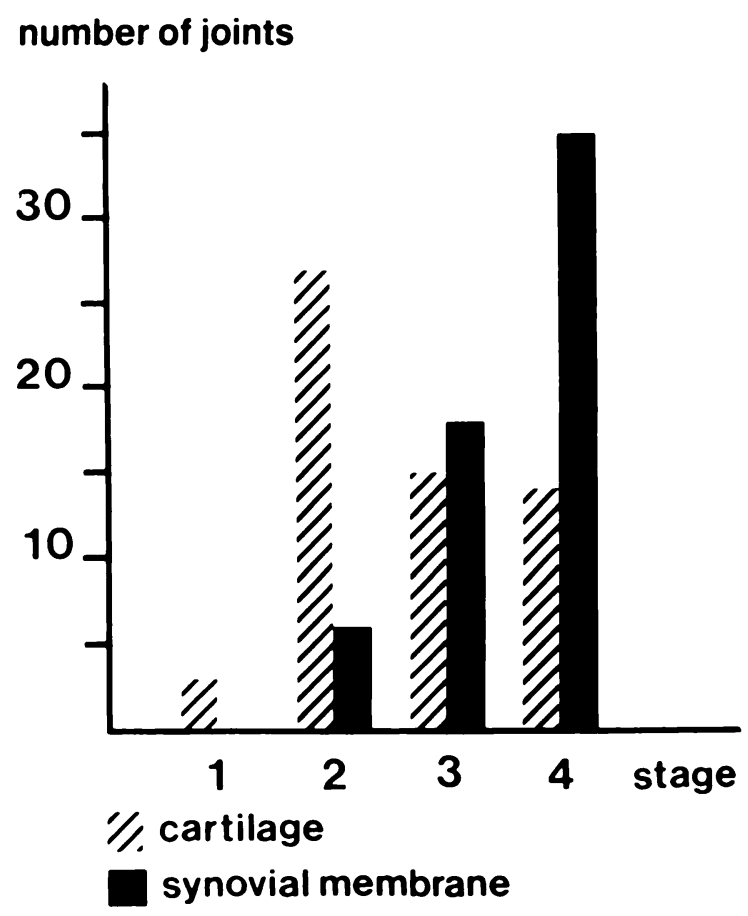

Fig. 3

Condition of the cartilage and the synovial membrane at operation on 59 knees. Stages $I$ to 4 are defined in the text.

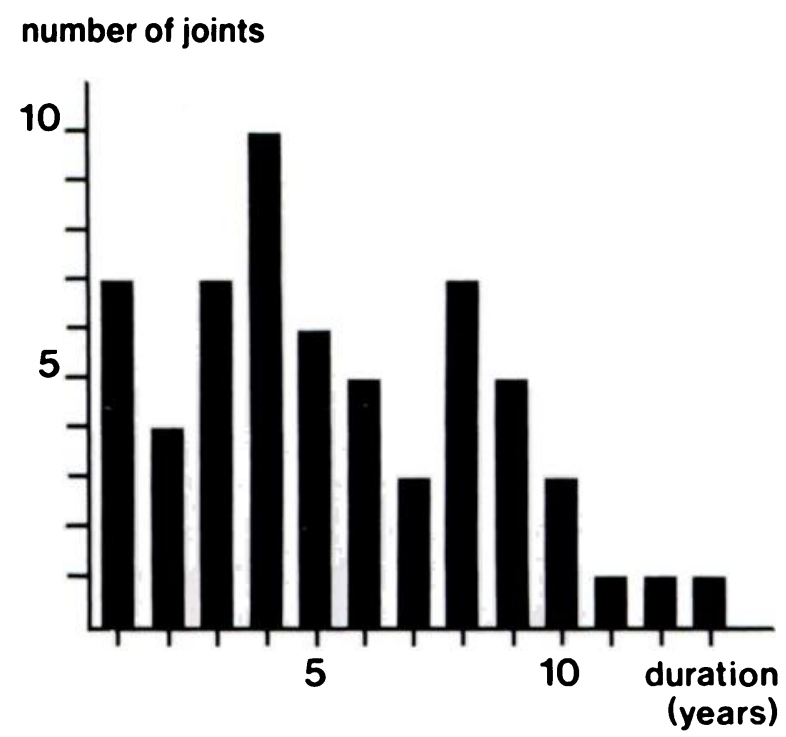

Fig. 2

Duration of arthritis in the joint at the time of synovectomy.

had not been achieved within two weeks of synovectomy. Recurrence of the synovitis was diagnosed when swelling of the knee, with or without effusion, returned after a period of complete remission. This definition meant that temporary flares as well as chronic recurrences were recorded.

At operation the condition of the articular cartilage and synovial membrane of the joint was recorded according to the stages of deterioration described by

\section{stage of cartilage \\ at operation}

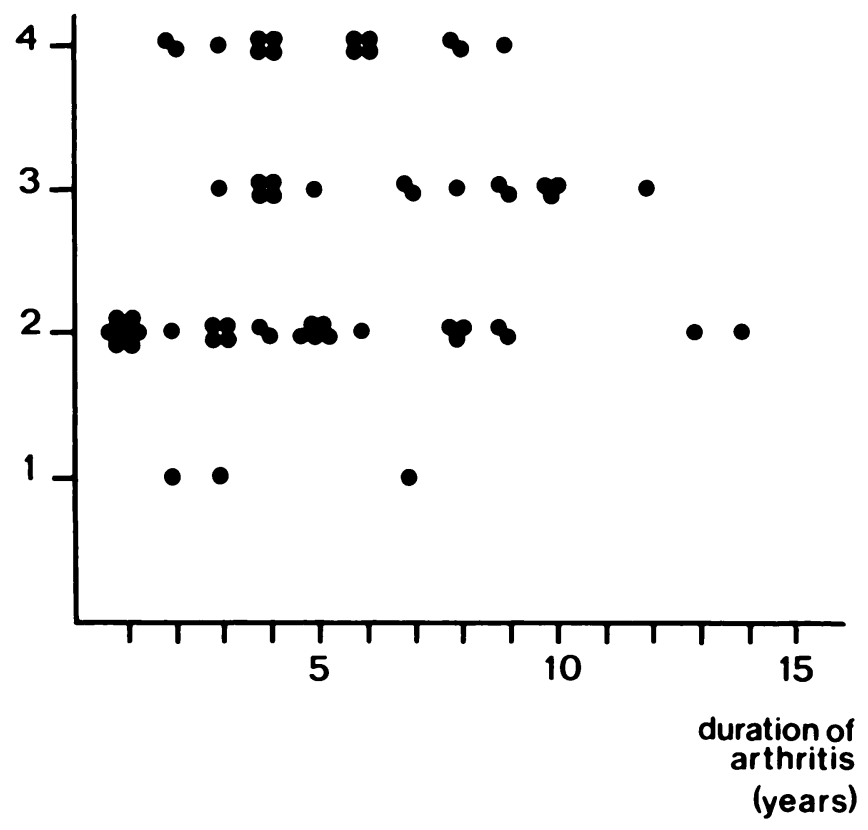

Fig. 4

Condition of the articular cartilage in 59 knees at operation, related to the duration of arthritis in the joint. 
Holgersson et al. (1981). For cartilage, a normal appearance was Stage 1, mild erosion with yellow areas and flaking was Stage 2, moderately large and deep cartilage erosions were Stage 3, while severe erosions through the cartilage, exposing or entering bone were classed as Stage 4. For synovial membrane, normal appearance was Stage 1, mild inflammation was Stage 2, moderate inflammation was Stage 3, while severe inflammation was recorded as Stage 4 .

The level of pain was recorded before and after operation; and disease activity was classified as "low" if the ESR was less than $50 \mathrm{~mm}$ in the first hour and the orosomucoid level was less than $2 \mathrm{~g} / \mathrm{l}$, and as "high" for values above these levels. These biochemical parameters are a crude and sometimes unreliable measure of disease activity, but other parameters of activity had not been systematically recorded.

Pre-operative radiographs, usually including an axial view of the patella, were available for $57 \mathrm{knees}$, and one or more postoperative radiographs were reviewed for 51 knees. These radiographs were scored according to Pettersson and Rydholm's grading (1984), zero denoting a radiographically normal joint and the maximum score of 15 points denoting ankylosis. Any subsequent operations on the synovectomised knees were recorded. Our statistical methods included univariate analysis, using the $\gamma^{2}$-test and the $t$-test, and multivariate analysis by logistic regression. All the reported $P$-values are twotailed, and the selected level of significance was $5 \%$.

\section{RESULTS}

Articular cartilage and synovial membrane. The condition of the cartilage and synovial membrane, graded in the stages given above, is shown in Figure 3. There was no correlation between the stage of cartilage damage and the duration of the synovitis (Fig. 4).

Early complications. Two patients had a superficial wound infection, which healed uneventfully with oral antibiotics. Manipulation under anaesthesia and mobilisation was needed for the 21 knees which failed to gain either 90 of flexion or their pre-operative flexion by two weeks after operation. None required a second manipulation.

Range of movement. Pre-operative and postoperative ranges of movement had been recorded for 56 knees. At the time of operation 19 knees had no extension deficit (no fixed flexion), while 19 had less than 10,12 from 10

to 19 and six had an extension deficit of 20 or more. Postoperatively there was some improvement: 26 knees had no extension deficit, 18 had less than 10,10 from 10 to 19 , while two knees still had an extension deficit of 20 or more.

Pre-operatively 42 knees had more than 110 flexion, while after operation 48 knees could flex this far. There was a clear relationship between the stage of cartilage destruction and the postoperative range of move-

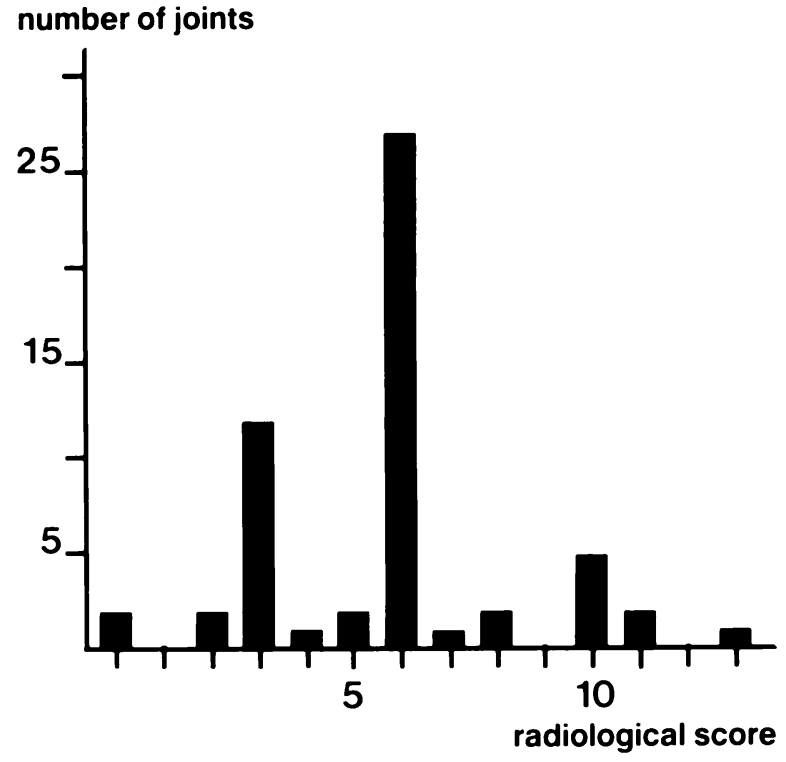

Fig. 5

Radiological scores at the time of operation for 57 knees. The scoring method is defined in the text.

ment both as regards flexion $(P=0.0005)$ and extension $(P=0.053)$.

Radiology. At the time of operation the radiological score varied from 0 to 13 points with a mean of 5.7 points (Fig. 5). Of 57 joints assessed, 46 scored six points or less. having no erosions or subchondral cysts. Knees known to have Stage 3 cartilage destruction had the same mean radiological score as joints with Stage 1 or 2 cartilage changes, while joints in Stage 4 scored slightly higher (Fig. 6). Follow-up radiographs were available for 51 knees; 5 of the 9 missing films were of patients with polyarticular disease. Of the 51 knees, 24 (18 in the systemic

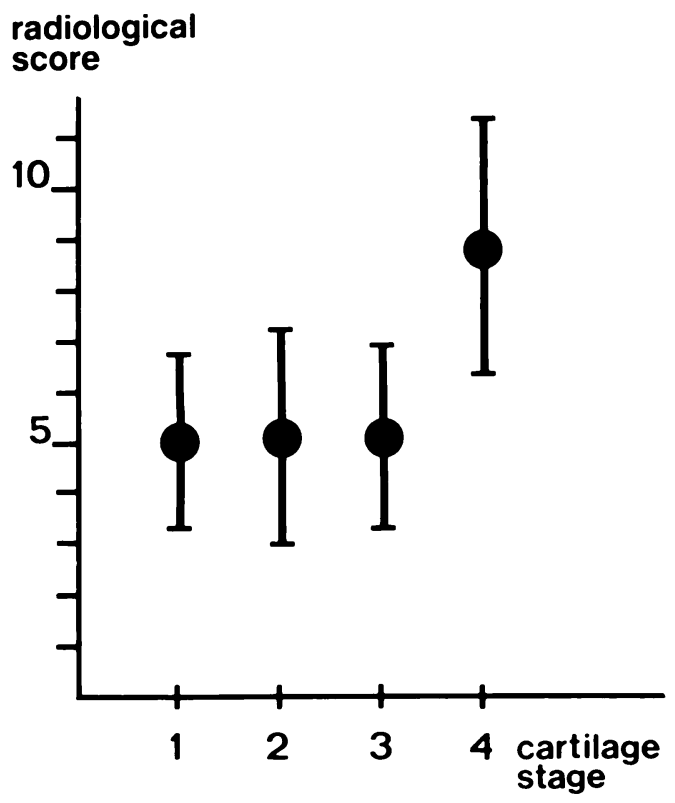

Fig. 6

Relation between the stage of destruction of the cartilage and the radiological score at the time of operation for $57 \mathrm{knees}$. 


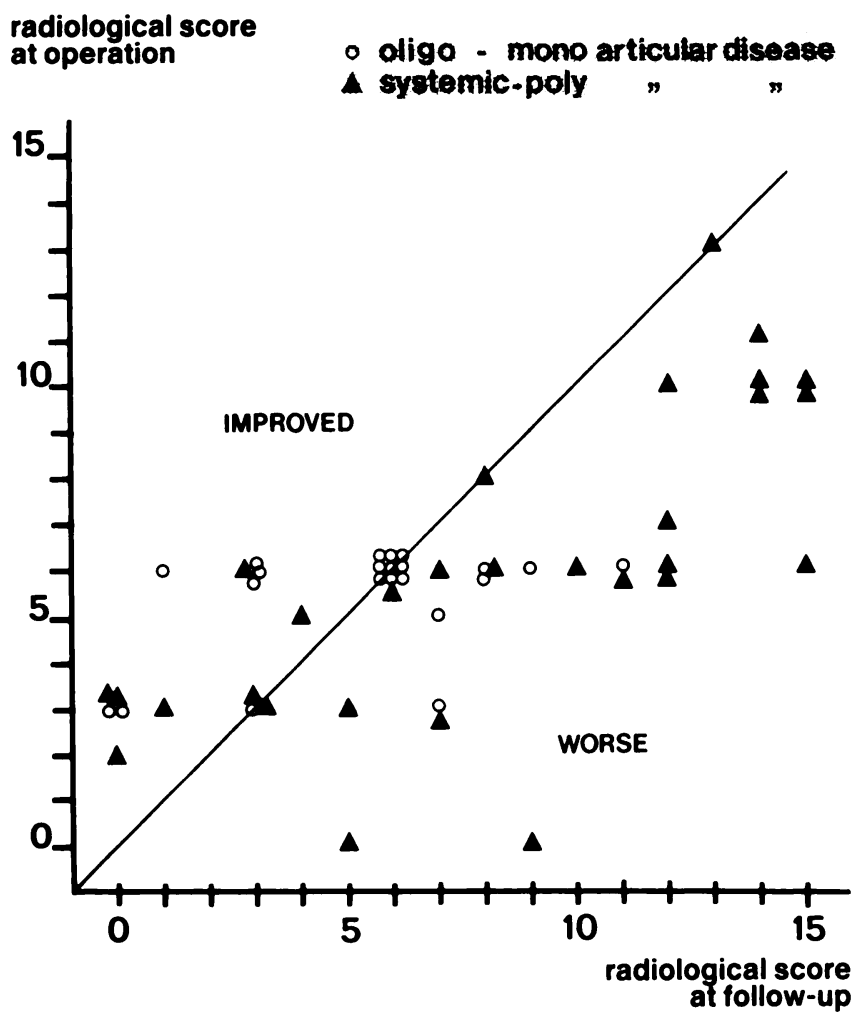

Fig. 7

Radiological scores at operation and at follow-up for 29 knees in patients with systemic or polyarticular disease and for $22 \mathrm{knees}$ in patients with oligo-articular or monarticular disease.

or polyarticular groups) suffered progressive radiographic destruction during follow-up, while 27 joints (11 in the systemic or polyarticular groups) improved or were unchanged. The mean deterioration during followup was 3.1 points (range -3 to +9 ) in the systemic or polyarticular groups as compared to 1.8 points (range -3 to +5 ) in the oligo-articular or monarticular groups of patients (Fig. 7). Patients with high disease activity at the time of operation had a higher score at follow-up than those with low activity $(P=0.0032)$ (Table I). The score at the time of operation could not be related to pain at follow-up or to the need for later operations, and there was no correlation between either age at the onset of disease or the duration of arthritis and the final radiological score.

Relapse. One or more relapses were seen in 34 knees during the follow-up period. No correlation could be found between the type of disease and the risk of relapse.

Subsequent operations. During the period of follow-up 11 knees had further operations. These included four softtissue releases, six cases in which medial stapling of one or both of the distal femoral and proximal tibial epiphyses was needed for progressive valgus deformity, and one total knee arthroplasty. The need for a second operation was not related to age at the primary operation nor to the activity of the disease at the time of synovectomy.

Pain. Of 60 knees, 48 were painful before operation and only 14 at follow-up. No correlation was found between pain and the activity of disease at the time of operation.

Disease activity. At the time of operation 40 knees were in patients with low disease activity and 20 in patients with high activity. At follow-up the pattern had changed, with 52 knees in the low activity group and only seven with high activity. Results were not available for one patient. High disease activity was seen more often in

Table I. The relation between disease activity at operation and the radiological score at follow-up in 49 knee joints

\begin{tabular}{llc} 
& Activity & \\
Radiograph & Low & High \\
\hline Unchanged or better & 20 & 5 \\
Worse & 10 & 14
\end{tabular}

patients with systemic or polyarticular disease than in those with oligo-articular or monarticular disease $(P=0.0003)$.

Factors influencing deterioration. Multivariate logistic regression analysis was used to find the faetors which were of significance for radiological deterioration, for pain, and for risk of relapse during follow-up. The risk of radiological deterioration (Fig. 8) diminished with higher age at operation regardless of the type of disease $(P=0.0119)$ or the activity of the disease at the time of operation $(P=0.0317)$. Systemic or polyarticular types 
of disease carried a higher risk of deterioration than oligo-articular or monarticular disease $(P=0.0497)$ and, similarly, high disease activity at operation implied a higher risk of deterioration than low activity $(P=0.0368)$. The risk of pain at the follow-up assessment was higher the older the patient was at the time of onset of disease $(P=0.019)$.

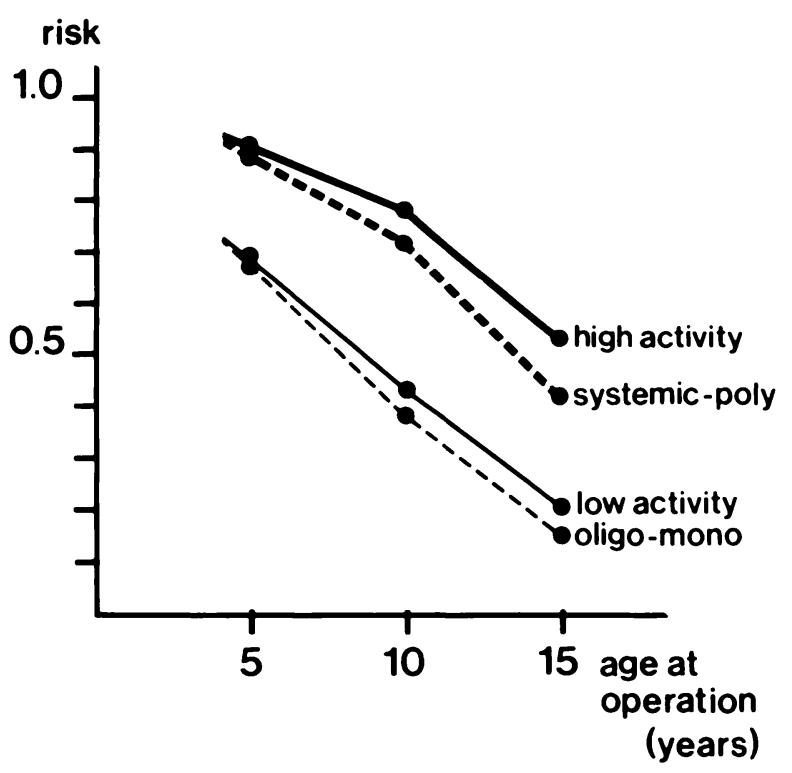

Fig. 8

Logistic regression analysis of the risk of radiological deterioration during follow-up, related to the activity and type of the disease and the age at operation.

The risk of relapse was higher for patients with high disease activity at operation $(P=0.029)$. Some relapses were successfully treated with intra-articular steroids; others responded to systemic drug treatment combined with physiotherapy. The risk of relapse had no relation to the pre-operative duration of the arthritis.

\section{DISCUSSION}

Differing opinions on the timing of synovectomy of the knee in patients with juvenile chronic arthritis can be found in the literature. Eyring et al. (1971) regard the presence of active synovitis with either joint erosions visible radiographically or significant loss of movement as indications for synovectomy regardless of the duration of disease. In the absence of both radiographic signs and significant loss of movement they consider that persistence of synovitis for 18 months is an indication for synovectomy. Roles (1978) recommended waiting one to two years in order to avoid unnecessary operations. He also noted good long-lasting functional results even when radiographic destruction had been seen before operation. McMaster (1972) recommended waiting for nine months before operation, but agrees with Jani and Waigand (1971) that synovectomy should be performed before radiographic erosions appear.

No conclusions on the timing of operation in relation to the onset of disease can be drawn from our mater- ial. Subchondral cysts and erosions are late to appear on radiographs because of the thick cartilage in children. The cartilage destruction found at operation far exceeded the radiographic findings; joints with Stage 3 cartilage destruction had the same radiological score as joints with Stage 1 and Stage 2 changes. The radiological score for joints with Stage 4 cartilage damage was only slightly higher (Fig. 6). No correlation was found between the state of the cartilage or the synovial membrane at operation and later radiological deterioration. The severity of cartilage destruction and synovitis in our series accord with the long, five-year, mean duration of synovitis before operation, but there was no correlation between this duration and the severity of cartilage destruction in individual cases (Fig. 4). This makes it even more difficult to decide the most suitable time for operation.

Kampner and Ferguson (1972) report better results in patients with oligo-articular or monarticular disease; this accords with our findings on the risk of radiological deterioration. Our study indicates that one to two years of systemic and local treatment for a young child are reasonable before surgical synovectomy is carried out, provided that there is no progressive deformity or leglength discrepancy. There need be no hesitation in operating on a young child for fear of postoperative limitation of movement.

The lack of relationship between radiological score and cartilage damage at operation means that arthroscopy may be of value in determining the degree of joint destruction and synovial inflammation. Arthroscopy could improve the timing of synovectomy and also make it possible to follow the results of a specific treatment. We have started a study on the relation between arthroscopic, radiographic and operative findings. Pain is one

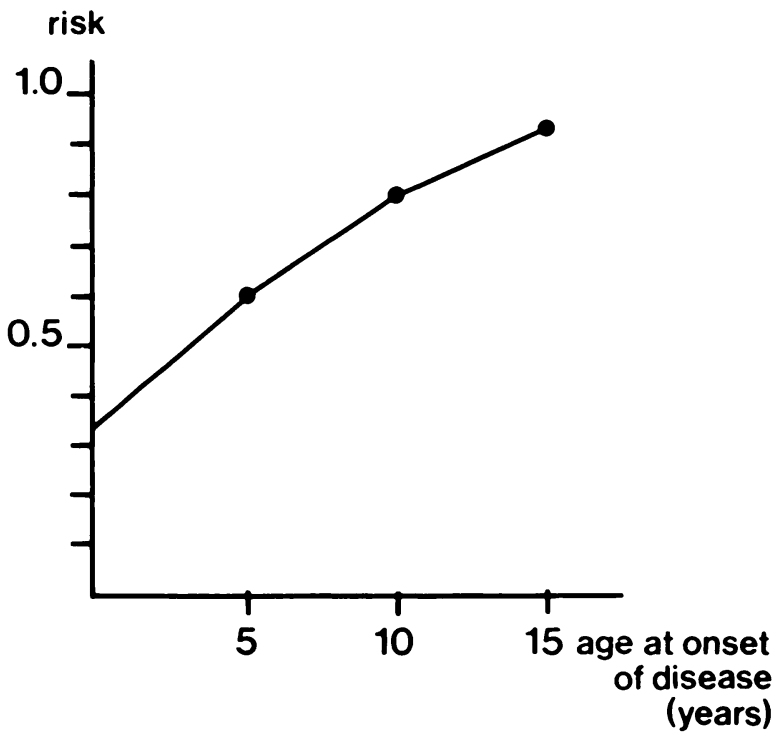

Fig. 9

Logistic regression analysis of the risk of pain at follow-up. related to the age at the onset of disease. 
of the indications for synovectomy; but we found that pain was not a reliable index of the biochemical activity of the disease. Pain relief at follow-up was highly satisfactory and was best in the children who were youngest at the onset of disease (Fig. 9).

Fink et al. (1969) found no correlation between the degree of joint destruction and the range of movement after synovectomy; some of the most severely affected joints gained a better range postoperatively than less involved joints. In our study patients with severe cartilage destruction gained less movement. Extension improved more than flexion and is the most important part of the functional range.

Eyring et al. (1971) found progressive radiographic destruction in 4 of 48 synovectomised joints ( 10 of them were knees) in patients with JCA. Twelve joints showed improvement and 32 were unchanged after a mean follow-up of two years. Fink et al. (1969) reported the healing of erosions and an apparent increase in joint space after synovectomy, while Berger et al. (1979) found unchanged or improved radiographs in 25 of 30 knees followed for more than three years after surgical synovectomy. We found an improved radiological score on follow-up in 12 of 51 joints and an unchanged score in 15 knees, most of which had oligo-articular or monarticular disease (Fig. 7). Fiszman, Ansell and Renton (1981) stated that the most pronounced radiographic changes were found in those patients in whom the disease commenced early in life but, apart from this, little is known about the natural course of radiological destruction in joints affected by JCA, and even less about the influence of synovectomy on the process. Our results agree with those of Fiszman et al. in showing a high risk of radiographic deterioration in younger patients, regardless of the type or activity of the disease at the time of operation.

The recurrence of swelling and joint effusion does not always mean that the operation was not worthwhile. Despite single relapses function may be maintained and the knee may be free of pain. It should. however, be noted that high activity of disease at the time of operation carries a higher risk of relapse. Our study confirmed the finding of McMaster (1972) that the duration of arthritis was not related to the long-term results of synovectomy.

The analysis of results by a multivariate logistic regression model are important even in the absence of results for an unoperated randomised control group of patients with juvenile chronic arthritis. It has shown the higher risk of radiographic deterioration in young patients with high disease activity and systemic or polyarticular types of disease, as against the older child with low activity and few affected joints. The optimal timing for synovectomy remains a difficult decision, and the evaluation of the prophylactic value of synovectomy on radiographic deterioration is not possible without more knowledge of the natural history of the disease.

The authors wish to acknowledge grants from the following: Stiftelsen Konsul Thure Carlssons Minne. Greta och Johan Kocks stiftelse, Alfred österlunds Stiftelse and Eugeniastiftelsen.

\section{REFERENCES}

Brattström H. (Co-ordinator). Long-term results of knee synovectomy in early cases of rheumatoid arthritis: a multi-center retrospective study presented by European Rheumatoid Arthritis Surgical Society (ERASS) at the Tenth European Congress of Rheumatology in Moscow 1983. Clin Rheumatol 1985:4:19-22.

Berger G, Lorenz K, Rupprecht E, Crasselt C. Röntgenologische Verlaufsuntersuchungen nach Synovektomic bei juveniler Rheumatoid-Arthritis. Kinderaer:ıl Prax 1979:47:30 7.

Eyring EJ. The therapeutic potential of synovectomy in juvenile rheumatoid arthritis. Arthritis Rheum 1968:11:688 92.

Eyring EJ, Longert A, Bass JC. Synovectomy in juvenile rheumatoid arthritis: indications and short-term results. J Bone Joint Surg $[\mathrm{Am}]$ 1971:53 A:638-51.

Fink CW, Baum J, Paradies LH, Carrel BC. Synovectomy in juvenile rheumatoid arthritis. Ann Rheum Dis 1969:28:612 6.

Fiszman P, Ansell BM, Renton P. Radiological assessment of knees in juvenile chronic arthritis (juvenile rheumatoid arthritis). Scand $J$ Rheumatol 1981:10:145-52.

Granberry WM. Synovectomy in juvenile rheumatoid arthritis. Arthritis Rheum 1977:20 March No. 2 (Suppl):561-4.

Granberry WM, Brewer EJ. Results of synovectomy in children with rheumatoid arthritis. Clin Orthop 1974:101:1206.

Holgersson S, Brattström H, Mogensen B, Lidgren L. Arthroscopy of the hip in juvenile chronic arthritis. J Pediatr Orthop 1981:1: 2738.

Jani L, Waigand D. Synovectomy of the knee joint in juvenile rheumatoid arthritis. Reconstr Surg Traumatol 1971:12:35 45.

Kampner S, Ferguson AB. Efficacy of synovectomy in juvenile rheumatoid arthritis. Clin Orthop 1972:88:94-109.

Laaksonen A-L. A prognostic study of juvenile rheumatoid arthritis: analysis of 544 cases. Acta Pediatr Scand 1966:Suppl 166.

McMaster M. Synovectomy of the knee in juvenile rheumatoid arthritis. J Bone Joint Surg [Br] 1972:54 B:263 71.

Pettersson H, Rydholm U. Radiologic classification of knee joint destruction in juvenile chronic arthritis. Pediatr Radiol 1984:14: 41921.

Roles NC. Synovectomy of the knee. In: Arden GP. Ansell BM, eds Surgical management of juvenile chronic polyarthritis. London: Academic Press: New York: Grune \& Stratton 1978:75-91.

Roles NC, Arden GP, Ansell BM. Synovectomy of the knee in juvenile chronic arthritis. J Bone Joint Surg [Br] 1978:60 B:1389.

Rydholm U, Boegård T, Lidgren $L$. Total knee replacement in juvenile chronic arthritis. Scand J Rheumatol 1985:14:329 35. 